\title{
PENGARUH JOB INSECURITY DAN KEPUASAN KERJA TERHADAP TURNOVER INTENTION PADA KARYAWAN HOTEL
}

\author{
A.A Gede Agung Januartha ${ }^{1}$ \\ I G.A Dewi Adnyani ${ }^{2}$ \\ ${ }^{1,2}$ Fakultas Ekonomi dan Bisnis Universitas Udayana (Unud), Bali, Indonesia \\ e-mail: agungjanuartha@yahoo.com
}

\begin{abstract}
ABSTRAK
Turnover intention akan berdampak bagi kinerja dan keberlangsungan perusahaan untuk kedepannya.Tujuan penelitian ini adalah untuk menganalisa pengaruh job insecurity dan kepuasan kerja terhadap turnover intention. Penelitian dilakukan di Hotel Grand Zuri Kuta, Kabupaten Badung, Bali. Jumlah responden yang di gunakan sebanyak 75 karyawan dengan menggunakan metode sensus. Metode analisis data yang digunakan adalah analisis regresi linier berganda. Pengumpulam data melalui, kuesioner dan wawancara. Hasil penelitian menunjukkan bahwa job insecurity berpengaruh secara positif dan signifikan terhadap turnover intention, dan kepuasan kerja berpengaruh negatif dan signifikan terhadap turnover intention. Untuk menurunkan tingkat turnover intention sangatlah penting untuk memeperhatikan keamanan dan kenyamanan dalam bekerja. Oleh karena itu sangat perlu untuk meminimalisir ancaman-ancaman sikis maupun psikologi terhadap karyawan karna akan berdampak pada kinerja dan juga menjadi acuan yang kuat untuk meminimalisir turnover intention. Selain keamanan dalam bekerja (job insecurity) kepuasan kerja juga menjadi acuan yang kuat dalam mempenguruhi intensi turnover intention. Oleh karena itu sangatlah penting untuk memperhatikan kepuasan kerja dari karyawan agar tingkat kepuasan karyawan tinggi, dengan demikian akan menunjukkan tingkat positif dari karyawan, baik terhadap pekerjaannya maupun lingkungannya.
\end{abstract}

Kata kunci: job insecurity, kepuasan kerja, turnover intrntion

\begin{abstract}
Turnover intention will affect the performance and sustainability of the company for the future. The purpose of this research is to analyze the influence of job insecurity and job satisfaction toward turnover intention. The research was conducted at Hotel Grand Zuri Kuta, Badung regency, Bali. The number of respondents in use as many as 75 employees by using the census method" Data analysis method used is multiple linear regression analysis. Data collecting through, questionnaires and interviews. The results showed that job insecurity had positive and significant effect on turnovrer intention, and job satisfaction had negative and significant effect on turnover intention. To lower the turnover intention rate it is important to pay attention to safety and comfort in working. Therefore it is very necessary to minimize the threats of cyclical and psychological to employees because it will impact on performance and also a strong reference to minimize turnover intention. In addition to job security (job insecurity) job satisfaction is also a strong reference in mempenguruh intention turnover intention. Therefore it is very important to pay attention to job satisfaction from employees to high employee satisfaction level, thus will show the positive level of employees, both to the work and environment.
\end{abstract}

Keywords: job insecurity, job satisfaction, intrntion turnover 


\section{PENDAHULUAN}

Turnover intention adalah kadar intensitas dari keinginan untuk keluar dari perusahaan, banyak alasan yang menyebabkan timbulnya turnover intention ini dan diantaranya adalah keinginan untuk mendapatkan pekerjaan yang lebih baik (Harnoto, 2002:2). Turnover menjadi isu yang penting dalam dunia kerja, ditemukan bahwa kepuasan kerja adalah prediktor yang tepat untuk mengukur tingkat turnover intention karyawan. Turnover dapat merugikan perusahaan karena setiap kali ada karyawan yang keluar dari perusahaan maka perusahaan akan membutuhkan biaya perekrutan, penyeleksian dan pelatihan lagi kepada karyawan baru (Cohen dan Ronit, 2007).

Turnover intention telah ditekankan sebagai faktor penting pemicu penurunan kinerja organisasi yang dipengaruhi oleh variabel yang beragam diorganisasi (Lambert et al., 2006). Turnover juga telah menjadi agenda riset yang penting untuk diteliti bagi pengembangan sumber daya manusia dan pengembangan organisasional (Baek-Kyoo dan Sunyoung, 2009). Keputusan karyawan atau kemauan karyawan untuk keluar dari organisasi selalu menjadi tanda tanya besar bagi organisasi (Mahdi et al., 2012). Turnover menjadi kendala yang harus diterima oleh semua organisasi, karena saat ini sulit mencari tenaga kerja yang memiliki keterampilan serta komitmen yang tinggi terhadap organisasi (Jehanzeb, 2013).

Masalah yang serius ketika kepuasan seseorang di dalam perusahaan tersebut tidak dipenuhi, misalnya mengakibatkan tingkat turnover, absensi dari karyawan yang cenderung tinggi dan pada akhirnya akan memiliki efek kepada 
kinerja dari perusahaan itu sendiri (Ejaz, 2008). Kepuasan kerja merupakan salah satu indikator dari perilaku karyawan yang berhubungan langsung dengan jasa yang diberikan oleh karyawan. Kepuasan kerja menjadi prediktor yang tepat untuk mengukur turnover intention karyawan dan kepuasan kerja selalu memiliki pengaruh negatif terhadap turnover intention dari karyawan (Chen, 2006; Yucel, 2012; Faisal et al., 2012).

Dua teori kepuasan kerja yang menjadi dasar penelitian adalah Teori Keadilan dan teori Kontrak Psikologi. Teori Keadilan (Equity Theory) berfokus pada perasaan pegawai yang dipengaruhi oleh ada tidaknya keadilan (equity) pada komponen utama dari kepuasan kerja, yaitu input (faktor bernilai yang mendukung pegawai), output atau hasil (sesuatu yang dianggap bernilai oleh pegawai) serta keadilan atau ketidakadilan itu sendiri (Rivai dan Sagala, 2009). Menurut Sinambela (2012), teori ini menyebutkan bahwa setiap individu akan membandingkan rasio input dan output atas dirinya dengan orang lain maupun terhadap pekerjaan sebelumnya. Perusahaan harus mampu menciptakan kepuasan kerja bagi karyawan demi meningkatkan kualitas layanan myang maksimal (Munhurrun et al., 2010). Karyawan dengan tingkat kepuasan rendah akan menunjukkan sikap negatif, baik terhadap pekerjaannya maupun terhadap lingkungan kerjanya, sehingga karyawan akan merasakan insecure dalam dirinya dan merasakan kegelisahan dalam pekerjaannya, hingga pada akhirnya karyawan akan memiliki niat untuk berpindah dan meninggalkan pekerjaannya (Hanafiah, 2014). Penelitian oleh Loi et al. (2012) mengemukakan dengan tingkat keadilan 
prosedural yang lebih tinggi pegawai akan lebih mudah untuk mengetahui dan"mengendalikan kelangsungan.

Teori kontrak psikologi (psychological contract theory) menyatakan bahwa kondisi ketidakpastian dalam organisasi akan menimbulkan berbagai masalah serius, salah satunya adalah job insecurity yang dapat berdampak pada kepuasan kerja pegawainya (Silla et al., 2010). Sora et al. (2010) menambahkan bahwa pegawai yang merasakan job insecurity tinggi akan memiliki kepuasan kerja yang rendah. Khususnya untuk studi ini, pemantauan keamanan pekerjaan akan tepat diklasifikasikan sebagai kegiatan self-regulatory (Tahira et al., 2001). Kang et al. (2012) menganggap ketidakamanan kerja sebagai suatu kegelisahan pekerjaan yaitu sebagai suatu pekerjaan dari keadaan yang terus menerus dan tidak menyenangkan.

Keamanan kerja menurut Borg dan Elizur (1992) didefinisikan sebagai harapan-harapan karyawan terhadap keberlangsungan pekerjaannya yang mencakup hal-hal seperti adanya kesempatan promosi, kondisi pekerjaan umumnya dan kesempatan karir jangka panjang. Karyawan yang menyandang status kontrak akan selalu dibayangi oleh perasaan ketidak pastian apakah mereka masih akan dipekerjakan di Hotel Grand Zuri atau tidak disetiap menjelang masa akhir kontrak. Permasalahan-permasalahan seperti job insecurity yang akan berdampak pada rendahnya tingkat kepuasan kerja karyawan didalam tempat kerjanya tersebut akan dapat mengakibatkan tingginya tingkat perputaran karyawan. Data turnover selama periode tahun 2015 sampai tahun 2016 seperti dalam Tabel 1 sebagai berikut. 
Tabel 1.

Data Turnover Karyawan Hotel Grand Zuri selama tahun 2015 sampai tahun 2016

\begin{tabular}{cccc}
\hline Tahun & Jumlah Karyawan & Karyawan Masuk & Karyawan Keluar \\
\hline 2015 & 81 & 8 & 3 \\
2016 & 86 & 0 & 11 \\
\hline
\end{tabular}

Sumber: HRD Hotel Grand Zuri, 2016

Tujuan penelitian ini untuk mengetahui pengaruh job insecurity terhadap turnover intention di Hotel Grand Zuri dan untuk mengetahui pengaruh kepuasan kerja terhadap turnover intention di Hotel Grand Zuri. Penelitian ini juga diharapkan dapat digunakan sebagai salah satu referensi dalam bidang ilmu manajemen sumber daya manusia yang terkait dengan job insecurity, kepuasan kerja, dan turnover intention. Penelitian ini diharapkan dapat menjadi bahan pertimbangan bagi pihak manajemen Hotel Grand Zuri dalam membuat kebijakan sumber daya manusia terutama yang berkaitan dengan job insecurity, kepuasan kerja, dan turnover intention.

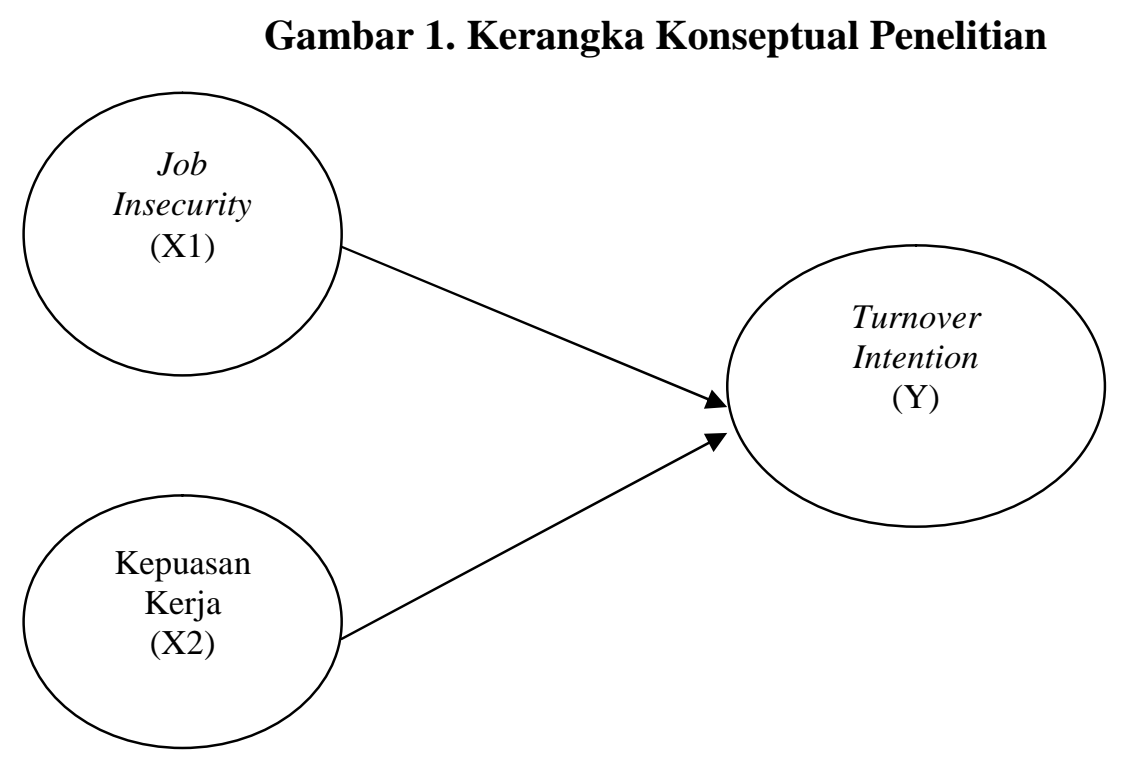


Turnover intention diartikan sebagai keinginan seseorang untuk tetap tinggal atau pindah dari organisasinya (Lum et al., 1998). Karyawan yang tidak puas dengan aspek-aspek pekerjaannya dan tidak memiiki komitmen terhadap organisasinya akan cenderung mencari pekerjaan (Andini, 2006). Istilah turnover berasal dari bahasa kamus Inggris Indonesia (John M.Echlos dan Hassan Shadily, 2003:608) berarti pergantian. Rasa ingin untuk berpindah kerja (turnover intention) merupakan permasalahan yang sangat serius dalam konteks manajemen SDM (Fah et al., 2010).

Menurut Sinem dan Baris (2011:4) mendefinisikan intention to turnover sebagai sikap perilaku seseorang untuk menarik diri dari organisasi, sedangkan turnover dianggap sebagai pemisahan yang sebenarnya dari organisasi. Turnover intention diklasifikasikan kedalam dua bagian, yaitu turnover tidak dapat di cegah dan turnover yang tidak diinginkan (Kumar et al., 2011). Turnover yang tidak dapat dicegah biasanya terjadi karena umur karyawan sudah di dalam kategori pensiun, atau karena mengalami penyakit, sedangkan turnover yang tidak diinginkan disebabkan oleh rasa yang kurang nyaman di dalam organisasi, kurangnya kompetensi dari karyawan tersebut di dalam menjalankan tugas, atau hubungan yang kurang baik dengan rekan kerja di tempat bekerja. Banyak aspek yang dapat memengaruhi turnover itu sendiri.

Aspek-aspek yang berkaitan di dalam pekerjaan salah satunya seperti kebebasan menentukan jadwal pekerjaan. Persepsi seseorang mengenai besarnya ancaman aspek-aspek pekerjaan dapat diketahui melalui seberapa besar aspekaspek itu dirasakan penting dan seberapa besar kemungkinan individu akan 
kehilangan aspek-aspek tersebut. Semakin penting dan semakin tinggi aspekaspek tersebut dipersepsikan mungkin hilang, maka semakin tinggi tingkat ancaman terhadap aspek-aspek dalam pekerjaan yag dirasakan individu tersebut.

Ancaman kehilangan pekerjaan secara keseluruhan merupakan persepsi seseorang mengenai adalanya kejadian-kejadian negatif yang dapat mempengaruhi pekerjaannya, seperti diberhentikan untuk sementara waktu. Ancaman tersebut dapat diketahui melalui seberapa penting dan seberapa mungkin kejadian-kejadian negatif tersebut dipersepsikan akan mempengaruhi pekerjaannya secara keseluruhan. Ketidakberdayaan menunjukkan ketidakmampuan seseorang untuk mencegah munculnya ancaman yang berpengaruh terhadap aspek-aspek pekerjaan dan pekerjaan secara keseluruhan. Semakin individu merasa tidak berdaya, semakin tinggi tingkat job insecurity.

Timbulnya gejala turnover biasanya ditandai dengan berbagai hal yang berhubungan dengan perilaku karyawan, seperti absensi yang meningkat, mulai malas bekerja, timbulnya keberanian untuk melanggar tata tertib, keberanian untuk menentang atasan, serta menurunnya keseriusan untuk menyelesaikan semua tanggu jawab yang diberikan (Hartono, 2002:2). Banyak hal yang dapat memengaruhi turnover intention menurut Novliadi (2007). Tingkat pendidikan berpengaruh pada dorongan untuk melakukan turnover. Dikatakan bahwa mereka yang mempunyai tingkat pendidikan tidak terlalu tinggi akan memandang tugastugas yang sulit sebagai tekanan dan sumber kecemasan. Sebaliknya mereka yang memiliki tingkat pendidikan yang lebih tinggi, akan lebih berani keluar dan mencari pekerjaan baru dengan mengandalkan tingkat pendidikan mereka yang 
lebih tinggi. Semakin tinggi keikatan seseorang terhadap perusahaannya akan semakin kecil ia mempunyai intensi untuk berpindah pekerjaan dan perusahaan, dan sebaliknya. Semakin tidak puas seseorang terhadap pekerjaannya akan semakin meningkat keinginan untuk melakukan turnover. Ketidakpuasan ini memiliki banyak aspek-aspek, yaitu ketidakpuasan terhadap manajemen perusahaan, kondisi kerja, mutu pengawasan, penghargaan, gaji/upah, promosi, dan hubungan interpersonal.

Menurut Poerwanto (2008:18) ada tiga tingkat dari budaya, yaitu: a) artifacts adalah produk nyata dari kelompok seperti arsitektur fisik, bahasa, teknologi, kreasi, tata ruang, cara berpakaian, cerita tentang mitos dan sejarah organisasi, serta perilaku; b) values merupakan sesuatu yang berharga untuk dipahami, dan dikerjakan sebagai landasan komitmen organisasi. Bentuk nyata dari nilai-nilai dapat berupa: filosofi, visi, disiplin kerja, sistem balas jasa, cara berinteraksi; c) basic underlying assumptions, adalah apa yang tidak disadari, akan tetapi secara nyata menentukan bagaimana anggota organisasi mengamati, berpikir, merasakan dan bertindak. Tindakan nyata dari asumsi dasar adalah keteladan, dan komunikasi dalam organisasi.

Mizar Yuniar (2008) mengartikan ketidakamanan kerja (job insecurity) sebagai kondisi psikologi seseorang (karyawan) yang menunjukan rasa bingung atau merasa tidak aman dikarenakan kondisi lingkungan yang berubah-ubah (perceved impermance). Menurut greenglass dkk., (2002) menurunnya kondisi psikologis seseorang akan mempengaruhi kepuasan kerja karyawan seperti perasaan tidak aman dalam bekerja (job insecurity) akan mempengaruhi keryawan 
lebih dari sekedar kehilangan pekerjaan semata. Menurut Svarke, Hellhren, dan Naswal (2002) dalam penelitiannya menemukan beberapa dampak pada karyawan dan organisasi dalam jangka pendek maupun jangka panjang. Menurutnya, dalam jangka pendek job insecurity akan berdampak dalam kepuasan kerja, keterlibatan kerja, komitmen organisasi dan kepercayaan terhadap pemimpin, seperti berkurangnya kepercayaan terhadap pemimpin sehingga berdampak pada kesalah pahaman antara pemimpin dan bawahan dalam hal pendapat. Sedangkan dalam jangka panjang akan berdampak terhadap kesehatan fisik, kesehatan mental, performa kerja, dan intensi pindah kerja (turnover).

Menurut Setiawan et al. (2012) job insecurity yang dirasakan pegawai dalam jangka panjang akan memberikan efek buruk pada performansi karyawanyang berakibat pada penurunan produktifitas organisasi. Job insecurity juga berdampak buruk pada kepuasan kerja dan sikap pegawai (Adkins et al., 2001). Gejala phisikologis dan fisiologis pada karyawan juga muncul karena adanya job insecurity (Mdrek, 2013).

Hasil penelitian Iriana et al. (2004), dan Ameen et al. (1995) pada akuntan pendidik menemukan bahwa job insecurity mempunyai hubungan positif terhadap keinginan berpindah kerja. Penelitian ini juga didukung oleh penelitian Suwandi dan Indriantoro (1999) yang menunjukkan bahwa job insecurity sebagai faktor yang secara langsung mempengaruhi keinginan berpindah kerja. Penelitian yang dilakukan oleh Gunalan dan Adnan (2015) menunjukkan bahwa job insecurity memliki pengaruh positif terhadap turnover intention. Hanafiah (2014) juga mendapatkan hasil penelitian serupa yang menyatakan bahwa ketidakaman kerja 
memiliki hubungan yang positif dengan turnover intention. Berdaarkan penelitian terdahulu, maka dapat dirumuskan hipotesis sebagai berikut: "

$\mathrm{H}_{1}$ : Job insecurity memiliki pengaruh positif dan signifikan terhadap turnover intention

Locke dalam Turkyilmaz et al. (2011) mengatakan bahwa kepuasan kerja merupakan suatu perasaan positif yang timbul dari karyawan sebagai hasil dari pengakuan terhadap pekerjaannya atau pengalamannya dalam bekerja. Persepsi ketidakamanan kerja telah dikaitkan dengan penurunan kepuasan kerja (De Witte, 2005). Afthartu (2011) juga menambahkan bahwa, pegawai yang merasakan keadilan dalam organisasinya juga akan dapat merasa lebih puas terhadap pekerjaan mereka.

Karyawan dengan tingkat kepuasan rendah akan menunjukkan sikap negatif, baik terhadap pekerjaannya maupun terhadap lingkungan kerjanya, sehingga karyawan akan merasakan insecure dalam dirinya dan merasakan kegelisahan dalam pekerjaannya, hingga pada akhirnya karyawan akan memiliki niat untuk berpindah dan meninggalkan pekerjaannya (Hanafiah, 2014). Kepuasan kerja telah berulang kali diidentifikasi sebagai alasan utama mengapa karyawan meninggalkan pekerjaan mereka (Mahdi et al., 2012). Namun banyak studi yang dilakukan di negara-negara barat secara konsisten menunjukkan pengaruh negatif dan signifikan antara kepuasan kerja dan turnover intention di kalangan karyawan (Salleh et al., 2012). Islam et al. (2012) yang melakukan riset serupa juga mengemukakan adanya hubungan yang negatif antara kepuasan kerja dengan turnover intention. Kepuasan kerja berpengaruh terhadap keputusan karyawan untuk tinggal atau meninggalkan organisasi, jika karyawan tidak puas dengan 
pekerjaan mereka, mereka cenderung akan meninggalkan organisasi, sebaliknya jika karyawan percaya bahwa mereka diperlakukan secara adil dan mendapatkan penghargaan, mereka tidak akan mungkin untuk meninggalkan organisasi (Aydogdu dan Asikgil, 2011). Berdasarkan landasan teori dan berbagai penelitian sebelumnya dapat dikemukakan hipotesis sebagai berikut:

$\mathrm{H}_{2}$ : Kepuasan kerja memiliki pengaruh negatif dan signifikan terhadap turnover intention.

\section{METODE PENELITIAN}

Penelitian ini bersifat asosiatif yang bertujuan untuk mengetahui pengaruh atau hubungan antara dua variabel atau lebih (Sugiyono, 2012:5). Metode penelitian menggunakan metode kuantitatif. Variabel dalam penelitian ini antara lain job insecurity, kepuasan kerja, dan turnover intention.Lokasi penelitian ini dilakukan di Hotel Grand Zuri yang berlokasi di Jl.Raya Kuta No. 81. Objek penelitian yaitu job insecurity, kepuasan kerja, dan turnover intention karyawan Hotel Grand Zuri.

Job insecurity dalam penelitian ini adalah bagaimana kondisi psikologi karyawan yang menunjukkan rasa bingung atau merasa tidak aman karena kondisi lingkungan yang berubah-ubah.Terdapat 3 indikator job insecurity dalam penelitian ini, menurut Adkins et al. (2001): 1). Ancaman terhadap aspek-aspek dalam pekerjaan.Aspek-aspek yang berkaitan di"dalam pekerjaan salah satunya sepertikebebasan menentukan jadwal pekerjaan. Persepsi seseorang mengenaibesarnya ancaman aspek-aspek pekerjaan dapat diketahui melalui seberapabesar aspek-aspek itu dirasakan penting dan seberapa besar kemungkinan 
individu akan kehilangan aspek-aspek tersebut. Semakin penting dan semakin tinggi aspek-aspek tersebut dipersepsikan mungkin hilang, maka semakin tinggi tingkat ancaman terhadap aspek-aspek dalam pekerjaan yag dirasakan individu tersebut; 2). Ancaman kehilangan pekerjaan secara keseluruhan.Ancaman kehilangan pekerjaan secara keseluruhan merupakan persepsi seseorang mengenai adalanya kejadian-kejadian negatif yang dapat mempengaruhi pekerjaannya, seperti diberhentikan untuk sementara waktu. Ancaman tersebut dapat diketahui melalui seberapa penting dan seberapa mungkin kejadian-kejadian negatif tersebut dipersepsikan akan mempengaruhi pekerjaannya secara keseluruhan; 3). Ketidakberdayaan menunjukkan ketidakmampuan seseorang untuk mencegah munculnya ancaman yang berpengaruh terhadap aspek-aspek pekerjaan dan pekerjaan secara keseluruhan. Semakin individu merasa tidak berdaya, semakin tinggi tingkat job insecurity.

Kepuasan kerja dalam penelitian ini adalah bagaimna keadaan emosional yang menyenangkan maupun tidak menyenangkan yang dialami oleh karyawan saat melakukan pekerjaannya dengan usahanya sendiri. Menurut Cekmecelioglu et al. (2012), kepuasan kerja memiliki beberapa indikator, yaitu: 1). Pekerjaan itu sendiri ( The work Itself) merupakan kepuasan kerja yang dirasakan karyawan terhadap pekerjaan yang dimilikinya berdasarkan persepsi mereka masing-masing; 2). Bayaran (Pay) merupakan kepuasan kerja yang dirasakan karyawan berupa gaji pokok yang diterimanya berdasarkan kontribusi yang sudah dia diberikan; 3). Kesempatan mendapatkan promosi jabatan (Promotion Oppertunities). Merupakan kepuasan kerja yang dirasakan karyawan karena memiliki kesempatan 
untuk mendapatkan tingkat jabatan yang lebih tinggi di suatu perusahaan; 4). Hubungan Kerja (Work Relation). Merupakan kepuasan kerja yang dirasakan karyawan berdasarkan peran rekan kerja dan atasan sebagai tenaga ahli yang menolong dalam pekerjaan dan perlakuan secara sosial yang dirasakan oleh karyawan.

Turnover Intention dalam penelitian ini adalah adanya keinginan atau niat karyawan untuk meninggalkan tempat dia bekerja sekarang ke tempat kerja yang baru. Adenguga et al. (2013) menyatakan variabel turnover intention mempunyai 3 indikator yang dijadikan sebagai dasar untuk mengukur keinginan untuk keluar tersebut, yaitu: 1). Munculnya keinginan meninggalkan perusahaan. Keinginan seseorang untuk meninggalkan perusahaan muncul dari hasil pemikiran karyawan itu sendiri, dimana pemikiran tersebut merupakan gambaran atau cerminan dari apa yang sudah dirasakan dan dilakukan selama bekerja sehingga menimbulkan keinginan untuk keluar dari perusahaan; 2). Munculnya keinginan untuk mencari pekerjaan baru, yakni keinginan untuk mencari pekerjaan baru dapat terjadi bila perusahaan tidak mampu memenuhi kebutuhan karyawannya sehingga karyawan akan cenderung untuk berpikir mencari alternatif pekerjaan pada perusahaan lain; 3). Keinginan untuk meninggalkan perusahaan dalam beberapa bulan mendatang, yakni karyawan akan termotivasi untuk mencari pekerjaan baru pada perusahaan lain dalam beberapa bulan mendatang yang dianggap bisa dan dapat memenuhi kebutuhan hidupnya.

Populasi penelitian ini adalah seluruh karyawan yang berjumlah 75 orang.Teknik sampling yang digunakan adalah teknik sampel jenuh dengan 
metode sensus. Respondennya adalah seluruh karyawan yang bekerja di Hotel Grand Zuri, sehingga responden dari penelitian ini adalah 75 orang.

Tabel 2.

Responden Berdasarkan Departement

\begin{tabular}{clc}
\hline No & Departemen & Jumlah Karyawan (orang) \\
\hline 1 & Administration dan General & 3 \\
2 & Accounting & 7 \\
3 & Sales dan Marketing & 3 \\
4 & Front office & 9 \\
5 & Housekeeping & 17 \\
6 & Food dan Bevarage Service & 9 \\
8 & Food dan Bevarage Production & 13 \\
9 & Engineering & 7 \\
10 & Human Resources Manager & 7 \\
& Total & 75 \\
\hline
\end{tabular}

Sumber: Data diolah, 2018

Wawancara merupakan metode pengumpulan data dengan cara tanya jawab langsung dengan beberapa karyawan berkaitan job insecurity, kepuasan kerja dan turnover intention. Kuesioner yaitu metode penelitian dengan menyebarkan daftar pernyataan secara tertulis, agar responden menjawab sendiri pertanyaanpertanyaan tersebut yang berkaitan dengan objek penelitian. Selanjutnya kuesioner akan diukur dengan menggunakan skala Likert. Data kuntitatif dalam penelitian ini adalah jumlah karyawan serta skor jumlah kuisioner yang telah dikalkulasi dengan pembobotan jawaban responden yang terdiri dari data turnover intention, kepuasan kerja dan job insecurity.

Data kualitatif merupakan data yang berbentuk kata, kalimat, skema dan gambar (Sugiyono, 2012:13). Data primer dalam penelitian ini adalah data yang didapat dari wawancara dan kuesioner yang disebarkan. Data sekunder dalam penelitian ini adalah keberadaaan perusahaan, jumlah karyawan, sejarah perusahaan, dan struktur organisasi. 
Penelitian ini menggunakan uji instrumen terlebih dahulu kemudian dilakukan uji asumsi klasik. Teknik analisis data yang digunakan dalam penelitian ini adalah model regresi linear berganda. Model regresi linear berganda dalam penelitian ini digunakan untuk mengetahui pengaruh job insecurity dan kepuasan kerja terhadap Turnover Intention. Model regresi linear berganda yang dimaksud, dirumuskan sebagai berikut:

$$
\mathrm{Y}=\mathrm{Bo}+\mathrm{B}_{1} \mathrm{X}_{1}+\mathrm{B}_{2} \mathrm{X}_{2}+\mathrm{e}
$$

\section{Keterangan:}

$\mathrm{Y} \quad=$ Turnover Intention.

$\mathrm{X}_{1}=$ Job insecurity

$\mathrm{X}_{2}=$ Kepuasan kerja

$\mathrm{Bo}=$ Intersep $\mathrm{Y}$

$\mathrm{B}_{1}=$ Koefesien Variabel $\mathrm{X}_{1}$

$\mathrm{B}_{2}=$ Koefesien Variabel $\mathrm{X}_{2}$

$\mathrm{e} \quad=$ Error of term (Variabel yang tidak terungkap)

\section{PEMBAHASAN}

Grand Zuri Kuta Bali merupakan hotel bintang 4 yang memiliki 133 kamar. Berlokasi ideal di jantung kawasan Kuta yang paling terkenal di Bali. Lokasi strategisnya memudahkan akses ke Pantai Kuta, Legian, Seminyak, dan Area Denpasar. Tepatnya di Jln Raya Kuta No 81 kuta, badung, bali. Didesain bagi pelancong liburan dan bisnis, Grand Zuri Kuta Bali merupakan pilihan akomodasi ideal. Urain tugas dan tanggung jawab berdasarkan struktur organisasi, pada Grand Zuri, General Manager yakni memimpin bawahannya dan menjadi motivator dalam meneglola perusahaan. Merencanakan kegiatan mengadakan koordinasi operasional usaha baik secara langsung maupun tidak langsung yang berhubungan kedalam maupun keluar perusahaan. Mengelola perusahaan sesuai 
dengan visi dan misi perusahaan. Bertanggung jawab terhadap perusahaan dan memberikan perlindungan kepada bawahan secara adil dan bijaksana. Executive Assistant Manager yang bertugas menjalankan perintah yang disampaikan oleh General Manager dan selanjutnya meneruskan kepada Manager. Menyampaikan laporan yang dibuat oleh para Manager. Mengambil alih tugas general manager apabila sewaktu-waktu General Manager berhalangan.

Assistant DOS dalam menentukan harga jual pruduk (playanan) yang akan di launching, jadwal kunjungan serta sistem promosi untuk memastikan tercapainya target, serta melakukan evaluasi kepuasan konsumen dari hasil survey seluruh sales team untuk memastikan tercapainya target kepuasan konsumen yang tlah ditentukan. Assistant SM, bertanggung jawab untuk mendapatkan pencapaian yang tinggi dalam keseluruhan proses Sales dan Marketing serta mengembangkan dan mempertahankan hubungan bisnis yang baik dengan klien maupun antar department. Reservation Sales Admin, bertaggung jawab untuk mengatur dan melakukan kegiatan administrasi untuk program-program Sales dan Marketing di bawah arahan Sales Manager dengan berpedoman pada kebijakan dan prosedur hotel. Assistant Front Office Manager, bertanggung jawab atas semua aktifitas di front office. Membuat laporan kamar check-in, check out dan reservasi. Memberikan informasi tentang pelayanan hotel.

FO supervisor, memeberikan layanan penerimaan dan keberangkatan tamu di hotel dengan memberikan petunjuk kepada staff front desk serta mengontrol kode akses di komputer di front desk. Dan menangani keluhan tamu yang tidak diatasi oleh FDA (front desk agent). FDA (front desk agent),menangani registrasi 
tamu, memberikan pelayanan sebelum tamu menginap serta menangani check out tamu beserta pembayarannya. Bellboy, mengantar tamu ke reception dan membawakan barang-barang tamu check in. Menerima kunci kamar dari receptionist kemudian mengantarkan tamu bersama barangnya ke kamar yang telah ditentukan.Public Area Attendant, bertanggung jawab menjaga kebersihan lobby area, kebersihan area karyawan, kebersihan area umum yang ada di hotel dan menjaga kebersihan loker karyawan. Gardener, bertanggung jawab atas segala kebersihan dan penataan area kebun atau taman yang ada di hotel. Chief Accountant, bertanggung jawab atas semua pendataan atau pengadministrasian transaksi dan keuangan. Mengawasi dan menjaga semua kegiatan transaksi. EDP/IA (elektronic data processing), menyampaikan informasi dan laporan yang baik serta tepat waktu untuk kebutuhan Internal maupun kebutuhan Eksternal Unit kerja yang bersifat rutin dan insidential.Cost Control, mengerjakan pekerjaan akuntansi dan lainnya yang berhubungan dengan keuangan sebelum terjadi transaksi dan memeriksa segala tagihan atau Invoice dari supplier sebelum dibayar. Purchasing Supervisor, memeriksa good request yang sudah disetujui untuk dicarikan barang ke supplier. Mengetahui segala harga-harga barang keperluan hotel guna pembuatan Purchase Order. Membuat summary purchase bulanan untuk dilaporkan kepada Fin Manager. General Chasier-AP, menyimpan uang kontan, buku-buku, check dan giro bilyet untuk pembayaran. Mengerjakan buku-buku harian kas dan bank. Menyetor dan mengambil uang di bank atas perintah atasan. Account Receivable, memeriksa semua data uang 
masuk/bill/outlet yang di dapat dari Night Audit. Memberikan bill cash kepada Book Keeter dan menyerahkan uang kontan kepada General Cashier.

Responden umur 31 - 40 sebanyak 15 orang (40\%) merupakan jumlah tertinggi dibandingkan dengan kelompok umur yang lain, hal ini mengindikasikan bahwa pihak hotel merekrut tenaga kerja yang memiliki kedewasaan dan produktif. Jumlah karyawan laki-laki lebih banyak dibandingkan dengan karyawan perempuan, hal ini dikarenakan karyawan laki-laki lebih diperlukan untuk mengisi shift malam dalam operasional hotel. Jumlah karyawan yang pendidikan perguruan diploma lebih banyak dari tingkat pendidikan lainnya hal ini mengidikasikan pihak hotel menginginkan perusahaan dioperasikan oleh tenaga kerja yang berpendidikan tinggi sesuai dengan bidangnya.

Pertama dilakukan uji instrumen yakni uji validitas bertujuan untuk menilai instrumen yang digunakan telah tepat untuk mengukur indikator dalam penelitian. Hasil pengukuran validitas masing-masing instrumen pada variabel disajikan dalam Tabel 3 sebagai berikut.

Tabel 3.

Hasil Uji Validitas

\begin{tabular}{cccc}
\hline Variabel & Indikator & $\begin{array}{c}\text { Pearson } \\
\text { Correlation }\end{array}$ & Keterangan \\
\hline \multirow{3}{*}{ Job Insecurity } & X.1 & 0,743 & Valid \\
(X1) & X.2 & 0,712 & Valid \\
& X.3 & 0,779 & Valid \\
X.1 & 0,594 & Valid \\
Kepuasan Kerja & X.2 & 0,562 & Valid \\
(X2) & X.3 & 0,793 & Valid \\
& X.4 & 0,813 & Valid \\
Turnover Intention & X.5 & 0,645 & Valid \\
(Y) & Y.1 & 0,649 & Valid \\
\hline Sumber: Data diolah, 2018 & Y.3 & 0,753 & Valid \\
\end{tabular}


Hasil uji validitas instrumen penelitian disajikan pada Tabel 3 yang menunjukkan bahwa seluruh indikator dalam variabel memiliki nilai Pearson Correlation yang lebih besar dari angka 0,30 sehingga seluruh indikator tersebut dikatakan telah memenuhi syarat validitas data.

Uji Reliabilitas bertujuan untuk mengukur konsistensi alat ukur yang digunakan. Hasil pengukuran reliabilitas masing-masing variabel disajikan dalam Tabel 4 sebagai berikut.

Tabel 4.

Hasil Uji Reliabilitas

\begin{tabular}{ccc}
\hline Variabel & Cronbadh'sAlpha & Keterangan \\
\hline Job Insecurity $(\mathrm{X} 1)$ & 0,799 & Reliabel \\
Kepuasan Kerja (X2) & 0,707 & Reliabel \\
Turnover Intention $(\mathrm{Y})$ & 0,725 & Reliabel \\
\hline
\end{tabular}

Sumber: Data diolah, 2018

Hasil uji reliabilitas instrumen pada penelitian ini disajikan pada Tabel 4 yang menunjukkan bahwa instrumen penelitian memiliki koefisien cronbach's alpha yang lebih besar dari angka 0,60 sehingga pernyataan pada kuesioner dapat dikatakan reliabel dan indikator yang digunakan merupakan indikator yang konsisten.

Selanjutnya dilakukan uji asumsi klasik yang meliputi uji normalitas, heteroskedastisitas dan multikolinearitas. Hasil uji normalitas dengan uji Kolmogorov-Smirnov diperoleh pada unstandarized residu nilai sig 0,114 lebih besar dari $\alpha=0,05$ artinya, data berdistribusi normal. Collinearity (multicollinearity) digunakan untuk menunjukkan adanya hubungan linear antara variabel-variabel bebas dalam model regresi. Biasanya korelasi mendekati sempurna atau mendekati satu antar variabel bebas. Uji multikolinieritas 
dilakukan dengan cara melihat Varians Inflation Factor (VIF).Adanya multikolinieritas sempurna akan berakibat koefisien regresi tidak dapat ditentukan serta standar deviasi akan menjadi tidak terhingga.

Demikian juga dengan nilai VIF yang semuanya di bawah 10. Hal ini berarti dalam model regresi tidak terjadi multikolinieritas. Variabel bebas tidak berpengaruh signifikan terhadap variabel terikat dari model regresi yang digunakan karena signifikansi setiap variabel bebas lebih dari taraf nyata $(\alpha)$ yaitu 5\%. Jadi dapat disimpulkan bahwa tidak terjadi heterokedastisitas.

Model yang digunakan dalam menganalisa pengaruh job insecurity, kepuasan kerja, terhadap turnover intention adalah model regresi linier berganda dengan bantuan SPSS versi 16.0 serta diuji dengan tingkat signifikansi 5\%. Dalam model regresi linier berganda ini, job insecurity $\left(\mathrm{X}_{1}\right)$, kepuasan kerja $\left(\mathrm{X}_{2}\right)$, digunakan sebagai variabel bebas, sedangkan turnover intention (Y) sebagai variabel terikat. Pada Tabel 5 berikut dapat dilihat hasil analisis pengaruh job insecurity, kepuasan kerja terhadap turnover intention.

Tabel 5.

Hasil Analisis Regresi Linier Berganda

\begin{tabular}{ccccc}
\hline Model & $\begin{array}{c}\text { Unstandardized } \\
\text { Coefficients }\end{array}$ & $\begin{array}{c}\text { Standardized } \\
\text { Coefficients }\end{array}$ & t & Sig.
\end{tabular}

\begin{tabular}{|c|c|c|c|c|c|c|}
\hline & & B & $\begin{array}{c}\text { Std. } \\
\text { Error }\end{array}$ & Beta & & \\
\hline \multirow[t]{6}{*}{1.} & Job insecurity & 0,987 & 0,084 & 0,914 & 11,767 & 0,00 \\
\hline & Kepuasan kerja & $-0,356$ & 0,063 & $-0,442$ & $-5,687$ & 0,00 \\
\hline & Konstanta & & & 6,599 & & \\
\hline & $R$ Square & & & 0,658 & & \\
\hline & $F_{\text {hitung }}$ & & & 69,266 & & \\
\hline & Sig. $F_{\text {hitung }}$ & & & 0,00 & & \\
\hline
\end{tabular}


Berdasarkan Tabel 5 diperoleh suatu persamaan regresi berganda sebagai berikut.

$$
\begin{aligned}
Y & =\alpha+\beta_{1} X_{1}+\beta_{2} X_{2} \\
& =6,599+0,987 X_{1}-0,356 X_{2}
\end{aligned}
$$

Berdasarkan hasil persamaan ini, dapat dijelaskan pola pengaruh job insecurity $\left(\mathrm{X}_{1}\right)$, kepuasan kerja $\left(\mathrm{X}_{2}\right)$, terhadap turnover intention $(\mathrm{Y})$ yaitu sebagai berikut: 1). $a=6,599$ berarti apabila job insecurity $\left(X_{1}\right)$, kepuasan kerja $\left(X_{2}\right)$, tidak mengalami perubahaan atau tetap maka besarnya turnover intention (Y) adalah 6,$599 ; 2) . b_{1}=0,987$ berarti apabila job insecurity $\left(X_{1}\right)$ dinaikkan satu satuan dan kepuasan kerja $\left(\mathrm{X}_{2}\right)$ tidak berubah maka turnover intention $(\mathrm{Y})$ naik sebesar 0,987 satuan. Artinya setiap peningkatan job insecurity dapat meningkatkan turnover intention; 3). $\mathrm{b}_{2}=-0,356$ berarti apabila kepuasan kerja $\left(\mathrm{X}_{2}\right)$ dinaikkan satu satuan dan job insecurity tidak berubah maka turnover intention (Y) turun sebesar 0,356 satuan. Artinya setiap peningkatan kepuasan kerja dapat menurunkan turnover intention. Hasil perhitungan nilai sig $<0,05$ maka Ho ditolak. Ini berarti bahwa pada tingkat kesalahan 5 persen job insecurity $\left(\mathrm{X}_{1}\right)$, kepuasan kerja $\left(\mathrm{X}_{2}\right)$, secara bersama-sama berpengaruh signifikan terhadap turnover intention.

Berdasarkan Uji F yang dilakukan didapatkan nilai signifikansi sebesar 0.00 yang berarti persamaan tersebut layak digunakan untuk memprediksi karena lebih kecil dari tingkat signifikansi sebesar 0.05 . Koefisien determinasi total sebesar 0,658, yang artinya sebesar $65.8 \%$ persen variasi turnover intention dipengaruhi oleh job insecurity dan kepuasan kerja, sedangkan sisanya sebesar 34,2 persen 
dipengaruhi oleh faktor-faktor lain yang tidak dimasukkan ke dalam model penelitian.

Job insecurity adalah suatu keadaan dimana seorang karyawan memiliki rasa tidak aman terhadap pekerjaan yang ia miliki. Rasa tidak aman itu bisa timbul karena adanya ancaman akan kehilangan dari pekerjaan tersebut ataupun kehilangan terhadap dimensi dari pekerjaan itu sendiri.Untuk mengatasi masalah job insecurity perusahaan harus melakukan berbagai cara untuk mencegah karyawannya pergi atau meninggalkan perusahaan terutama karyawan yang berkualitas dan menjadi tulang punggung perusahan.

Berdasarkan hasil pengujian secara empirik didapat job insecurity secara parsial berpengaruh positif sigifikan terhadap turnover intention. Hal ini berarti semakin tinggi job insecurity dapat mengakibatkan tingginya turnover intention begitu sebaliknya semakin rendah job insecurity dapat menurunnya turnover intention pada karyawan.

Berdasarkan pengujian data yang telah dilakukan didapatkan jawaban untuk pengujian hipotesis kedua yaitu mengenai pengaruh positif antara job insecurity terhadap turnover intention karyawan pada hotel Grand Zuri adalah benar atau dengan kata lain pengujian hipotesis kedua dapat diterima.

Hasil penelitian Ameen et al. (1995) dan Iriana et al. (2004) pada akuntan pendidik menemukan bahwa job insecurity mempunyai hubungan positif terhadap keinginan berpindah kerja. Penelitian ini juga didukung oleh penelitian Suwandi dan Indriantoro (1999) yang menunjukkan bahwa job insecurity sebagai faktor yang secara langsung mempengaruhi keinginan berpindah kerja. 
A.A Gede Agung Januartha. Pengaruh Job Insecurity...

Kepuasan kerja ditentukan oleh beberapa faktor yakni kerja yang secara mental menantang, kondisi kerja yang mendukung, rekan kerja yang mendukung, serta kesesuaian kepribadian dengan pekerjaan. Luthans (2008) menyebutkan bahwa kepuasan kerja merupakan keadaan emosi yang senang atau emosi yang positif yang berasal dari penilaian kerja atau pengalaman kerja seseorang. Berdasarkan hasil pengujian secara empirik didapat nilai sig $<0,05$ maka $\mathrm{H}_{1}$ diterima. Ini berarti pada tingkat kesalahan 5 persen, kepuasan kerja secara parsial berpengaruh negatif sigifikan terhadap turnover intention. Hal ini berarti semakin tinggi kepuasan kerja dapat mengakibatkan menurunkan turnover intentionbegitu sebaliknya semakin rendah kepuasan kerja dapat meningkatkan turnover intention pada karyawan.

Karyawan dengan tingkat kepuasan rendah akan menunjukkan sikap negatif, baik terhadap pekerjaannya maupun terhadap lingkungan kerjanya, sehingga karyawan akan merasakan insecure dalam dirinya dan merasakan kegelisahan dalam pekerjaannya, hingga pada akhirnya karyawan akan memiliki niat untuk berpindah dan meninggalkan pekerjaannya (Hanafiah, 2014). Kepuasan kerja telah berulang kali diidentifikasi sebagai alasan utama mengapa karyawan meninggalkan pekerjaan mereka (Mahdi et al., 2012). Namun banyak studi yang dilakukan di negara-negara barat secara konsisten menunjukkan pengaruh negatif dan signifikan antara kepuasan kerja dan turnover intention di kalangan karyawan (Salleh et al., 2012). Kepuasan kerja berpengaruh terhadap keputusan karyawan untuk tinggal atau meninggalkan organisasi, jika karyawan tidak puas dengan pekerjaan mereka, mereka cenderung akan meninggalkan 
organisasi, sebaliknya jika karyawan percaya bahwa mereka diperlakukan secara adil dan mendapatkan penghargaan, mereka tidak akan mungkin untuk meninggalkan organisasi (Aydogdu dan Asikgil, 2011).

\section{SIMPULAN DAN SARAN}

Berdasarkan hasil analisis dan pembahasan mengenai pengaruh job insecurity dan kepuasan kerja, terhadap turnover intention karyawan Hotel Grand Zuri maka dapat ditarik kesimpulan sebagai berikut: 1). Job insecurity secara parsial berpengaruh positif terhadap turnover intention; 2). Kepuasan kerja secara parsial berpengaruh negatif terhadap turnover intention.

Job insecurity berpengaruh positif sigifikan terhadap turnover intention. Hal ini berarti semakin tinggi job insecurity dapat mengakibatkan tingginya turnover intention begitu sebaliknya semakin rendah job insecurity dapat menurunnya turnover intention pada karyawan. Oleh karena itu sangat perlu untuk meminimalisir ancaman-ancaman terhadap karyawan karna akan berdampak pada kinerja karyawan itu sendiri. Kepuasan kerja berpengaruh negatif sigifikan terhadap turnover intention. Hal ini berarti semakin tinggi kepuasan kerja dapat mengakibatkan menurunkan turnover intention begitu sebaliknya semakin rendah kepuasan kerja dapat meningkatkan turnover intention pada karyawan.

Oleh karena itu sangatlah penting untuk memperhatikan kepuasan kerja dari karyawan agar tingkat kepuasan karyawan tinggi, dengan demikian akan menunjukkan tingkat positif dari karyawan, baik terhadap pekerjaannya maupun lingkungannya. Salah satunya dengan memberikan pengakuan seperti rewerd 
ataupun bonus dengan demikian karyawan akan merasa dihargai oleh perusahaan dan otomatis karyawan akan bekerja lebih maksimal.

Untuk meminimalisir turnover intention gaji merupakan faktor yang cukup penting. Sudah seharusnya pihak hotel memberikan gaji yang sesuai UMR atau UMK. Grand Zuri Kuta merupakan hotel bintang empat, dengan demikian karyawan Grand Zuri seharusnya mendapat minimal gaji yang sama dengan karyawan hotel yang berbintang empat yang ada di bali.

\section{DAFTAR RUJUKAN}

Adkins, Eric L. Gelke, Diane Rowe, and Rodney L. Honeycutt, (2001). Molecular Phylogeny and Divergence Time Estimates for Major Rodent Groups: Evidence from Multiple Genes, Mol. Biol. Evol. 18(5):777-791.

Adenguga, R. Alaba, Adenuga F. Titilola, and Ayodele K. O. (2013). Organizational Commitment and Turnover Intention among 'Private Universities' Employees in Ogun State, Nigeria. Open Journal of Education. 1(2), pp : 31-36

Agung A. W. S. Waspodo, Rianti Anggraeni. (2013). Pengaruh Karakteristik Pekerjaan Dan Iklim Komunikasi Terhadap Kepuasan Kerja Karyawan Operator Bagian Trimming I Pt Krama Yudha Ratu Motor, Jurnal Riset Manajemen Sains Indonesia (JRMSI)|Vol. 4, No. 2,.

Ameen, Elsie C., Chynthia Jackson, W.R Pasewark, and J.R Strawser. (1995). "An Empirical Investigastion of The Antecedents And Consequences of Job Insecurity on The Turnover Intentions of Academic Accountants." Issues in Accounting Education, 10, No.1 : 65-82.

Aydogdu, S. and Baris Asikgil. (2011). An Empirical Study of the Relationship among Job Satisfaction, Organizational Commitment and Turnover Intention. International Journal of Management and Marketing, 1(3) : 43-53

Booth, Kristian Hamer.(2007). Labour turnover in the retail industry: Predicting the role of individual, organisational and environmental factors", International Journal of Retail dan Distribution Management, Vol. 35 Iss: 4, pp.289- 307.

Borg, I and Elizur, D. (1992). Job Insecurity; Correlates, Moderators And Measurement; Journal International of manpower. Vol.13 No2; p. 13-26. 
Baek-Kyoo (Brian) Jooa, Huh-Jung Hahnb and Shari L. Petersonb. (2015). Turnover intention: the effects of core self-evaluations, proactive personality, perceived organizational support, developmental feedback, and job complexity, Human Resource Development International, Vol. 18, No. 2, 116-130.

Chen, Ching-fu. (2006). Job Satisfaction, Organizational Commitment, and Flight Attendant's Turnover Intention: A note. Journal of Air Transport Management, 12 (1), pp: 274-276

Chia, Ju-Lu. (2013). Effeccts Of Emotional Labor And Jobs Atisfaction On Organizational Citizenship Behaviors: A Case Study On Business Hotel Chains. International Journal of Organizational Innovation, 5(4):165-176.

Davis, R., Sajtos, L., and Ali Chaudari, A. (2011). "Do Consumer Trust Mobile Advertising Service?" Contemporary Management Research.Vol 7. No 4. Pages 245-270.

Fah, Foon, S.Y., Leong, C., dan Osman, S. (2010). An Exploratory Study on Turnover Intention among Private Sector Employees. International Journal of Business and Management, Vol. 5 (8): 57-64.

Greenglass and Lisa Fiksenbaum. (2009). Proactive Coping, Positive Affect, and Well-Being, European Psychologist; Vol. 14(1):29-39.

Gunalan, Mustafa., and Adnan Ceylan. (2015). The Mediating Effect of Organizational Support between Job Insecurity and Turnover Intention in Private Hospitals. International Journal of Business and Management, 10(10): 74-86

Hanafiah. (2014). Pengaruh Kepuasan Kerja Dan Ketidakamanan Kerja (Job Insecurity) Dengan Intensi Pindah Kerja (Turnover) Pada Karyawan Pt. Buma Desa Suaran Kecamatan Sambaliung Kabupaten Berau, eJournal Psikologi, 1 (3): 303-312.

Iriana, Prapti. Lilis Wijayanti dan Inon Listyorini. (2004). "Pengaruh Faktor Job Insecurity, Kepuasan Kerja, dan Komitmen Organisasi Terhadap Turnover Intention Akuntan Pendidik.” KOMPAK, No. 11 (Mei-Agustus): 284-296.

Islam, Talat., S.R. Khan., Muhammad Amir., and U.N.U. Ahmad. (2012). Turnover Intention: the influence of organizational learning culture and multi foci citizenhip behaviors. Middle-East Journal of Scientific Research, 12(5): 650-661.

Judge and Joyce E. Bono. (2001). Relationship of Core Self-Evaluations TraitsSelf-Esteem, Generalized Self-Efficacy, Locus of Control, and Emotional Stability_With Job Satisfaction and Job Performance: A Meta-Analysis, Journal of Applied Psychology, Vol. 86, No. 1, 80-92. 
Kang, D., Gold, J., and Daewon Kim. (2012). Reponses to job insecurity the impact on discretionary extra-role and impression management behaviours and the moderating role of employability. Journal Carrer Development International, 17(4), pp : 314-332.

Kazimati, Mimoza. (2011). Job Satisfaction And Turnover Under The Effect Of Person Organization Fit In Albanian Public Organizations. Journal for East European Management Studies, 16(4), 315-337.

Loi, Lam R., Long W. dan Chan, Ka wai. (2012). Coping With Job Insecurity: The Role Of Procedural Justice, Ethical Leadership and Power Distance Orientation. Journal Business Ethics, 108, pp: 361-372.

Lum, L., Kervin, J., Clark, K., Reid, F., and Sirola, W. (1998). Explaining nursing turnover intent: job satisfaction, pay satisfaction, or organizational commitment?. Journal of Organizational Behavior, 19 (3), 375-399.

Mahdi, Abishek S. Madduri, Guoqing Wang, Yael Strulovici-Barel, Jacqueline Salit, Neil R. Hackett, Ronald G. Crystal and Jason G. Mezey, (2012). Empirical Bayes conditional independence graphs for regulatory network recovery, Vol. 28 no. 15, pages 2029-2036.

Nugraha, A., dan Intan Ratnawati. (2010). Analisis pengaruh ketidakamanan kerja dan kepuasan kompensasi terhadap kinerja karyawan (studi pada karyawan PT. Bank Rakyat Indonesia Cabang Semarang Patimuan dan unit kerjanya). Disertasi. Fakultas Ekonomi Universitas Diponogoro Semarang.

Prastiti, Sawitri Dwi. (2002). Pengaruh Outcomes Job Insecurity Terhadap Turnover Intentions Dosen Akuntansi di Perguruan Tinggi. Masters thesis, program Pascasarjana Universitas Diponegoro.

Robbins, Stephen P. (2008). Organizational Behaviour12th edition. Jakarta: Salemba Empat.

Salleh, R., Mishaliny S. N., and Haryanni Harun. (2012). Job satisfaction, organizational commitment and turnover intention: a case study on employees of retail company in Malaysia. International Journal of Social, Behavioral, Educational, Economic and Management Engineering, 6(12): 702-709

Sora, Beatriz, Amparo Caballer dan Jose Maria Peiro. (2010). The Consequences of Job Insecurity For Employees: The Moderator Role of Job Dependence. Journal Compilation International Labour Organization, 149 (1), pp: 449465.

Sinem dan Baris. (2011). An Empirical Study of the Relationship Among Job Satisfaction, Organizational Commitment and Turnover Intention. International Review of Management and Marketing. Vol. 1, No. 3. 
Silla, Inmaculada, Gracia, Francisco J., Mañas, Miguel Angel dan Peiró, José M. (2010). Job Insecurity An Employees Attitude: The Moderating Role of Fairness. International Journal of Man Power, 31 (4), pp: 449-465

Sumarto, (2009). Meningkatkan Kompensasi, Kepuasan Kerja Dan Motivasi Untuk Mengurangi Labor Turnover Intention, Jurnal Riset Ekonomi dan Bisnis Vol. 9 No.1: 90-101.

Suwandi dan Nur Indriantoro. (1999). Pengujian Model Turnover Pasewark dan Strawser: Studi Empiris Pada Lingkungan Akuntan Publik. Jurnal Riset Akuntansi Indonesia 2, No. 2 : 173-195.

Sugiyono. (2012). Metode Penelitian Bisnis. Bandung: Alfabeta.

Sverke, M. danHellgren, J. danNaswall, K. (2002). No security: A meta-analysis and review of job insecurity and its conseqyences. Journal of Occupational Health psychology, 7(3), 242-264.

Tahira M. Probst and Ty L. Brubaker. (2001). The Effects of Job Insecurity on Employee Safety Outcomes: Cross-Sectional and Longitudinal Explorations, Journal of Occupational Health Psychology, Vol. 6, No. 2, 139-159.

Yucel, I. (2012). Examining the Relationship among Job Satisfaction, Organizational Commitment, and Turnover Intention: An Empiricial Study. International Journal of Business and Management, 7 (20), pp: 44-58. 